\title{
Daylight And Seating Preference In Open-Plan Library Spaces
}

\author{
Zeynep Keskin ${ }^{1}$, Yunhao Chen ${ }^{1}$, Steve Fotios ${ }^{1, *}$ \\ School of Architecture, the University of Sheffield, UK
}

Received 6 June 2015, Revised 7 July 2015, Accepted 26 August 2015

\begin{abstract}
Daylight factor has long been the predominant metric to evaluate daylight performance. Recently, the profession has moved toward annual dynamic daylight metrics such as useful daylight illuminance and daylight autonomy, which are based on absolute values of time varying daylight illuminance for a period of full year. As opposed to static daylight metrics that only concentrate on individual sky conditions, such as the widely used daylight factor, these metrics provide a more comprehensive way to measure illuminance for a wide range of sun positions and sky conditions. Although there is a growing consensus assigning importance to dynamic daylight metrics, there is no common understanding of how to integrate the preference and behaviour of building occupants in assessing the applicability of these metrics. In fact, it is when these occupancy observations and quantitative measurements are taken together that the importance of daylight performance metrics is fully realized. This study seeks to investigate the extent to which the influence of daylight on behaviour can be predicted, and for this the behaviour investigated is seating preferences of occupants in open plan, hot-desking spaces in two university libraries in Sheffield: Western Bank Library and the Information Commons. The results suggest that the association between daylight and seat choice may not be strong, and that any effect is better associated with daylight factor than with useful daylight illuminance or daylight autonomy.
\end{abstract}

Keywords: daylight, occupant behaviour, seat preference, daylight metrics

\section{Introduction}

Daylight can be defined as the visible part of the global solar radiation, and it has two components: sunlight and skylight. Sunlight refers to the direct solar beam, arriving directly at the earth's surface. Skylight, sometimes known as 'diffuse skylight', is the light from the sun scattered in the atmosphere before reaching the Earth's surface, and it is determined by sky conditions [1]. For daylighting design, it is important to maximize the penetration of diffuse skylight and block the direct sunlight as it causes discomfort through heating and glare.

As a dynamic tool for expressing the quality of space, daylight not only remains a potentially substantial source of illumination but necessarily imposes a creative discipline on architectural design. From its early stages of conception and development, daylight should dictate the quality of the architectural space, ultimately leading to a visual environment which is healthy, inspiring and stimulating for the occupants. The effective use of daylight becomes even more important for spaces where people spend most of their time performing visual tasks such as reading and writing, as these activities require certain amount of daylight.

\footnotetext{
* Corresponding Author: Steve Fotios Tel.: +44-114-222-0371.

E-mail address: steve.fotios@sheffield.ac.uk
} 
In order to use the potential benefits and attributes of daylight in design practice, a set of daylight performance metrics have been developed. While these metrics predict the physically available amount of daylight in a building, field studies are necessary to understand how people tend to respond to changing indoor illuminance distributions, i.e. where they prefer to sit in the room. This study examined the influence of daylight on occupant behaviour where occupant behaviour was defined as seat choice in an open plan daylit space. Daylight was analysed using three metrics; (i) daylight factor, (ii) useful daylight illuminance, and (iii) daylight autonomy.

\section{Daylight Performance Metrics}

In order to use the potential benefits and attributes of daylight in design practice, it can be helpful to translate them into a set of metrics [2]. For daylighting design, quantitative evaluations using these metric values can be performed for relative comparisons between alternative design solutions or for an absolute comparison against a benchmark value [2].

The most common daylight metric is daylight factor (DF), defined as the ratio of the daylight illuminance at a particular point on a horizontal plane to the simultaneously occurring external illuminance of the unobstructed overcast sky [3]. Daylight factor is limited because it depends on a single sky condition and it does not take into account climate, building location or orientation. To overcome such limitations two new metrics are proposed; Useful Daylight Illuminance (UDI) and Daylight Autonomy (DA) [4]. Both metrics consider variation in daylight over a whole year, using real weather data. Daylight autonomy indicates the percentage of the year when a minimum illuminance threshold is met by daylight alone; typically this threshold is 300 lux. However, too much light can be problematic, for example leading to glare, to blinds being drawn, and thus daylight being excluded. Thus UDI identifies the annual occurrence of illuminances across the work plane that are within a range considered "useful" for occupants $[4,5]$. The useful range is typically considered to be in the range of 300 to 3000 lux.

It has to be noted that the determination of target values for daylight performance metrics can be a challenge as it is highly dependent on the space type, specific visual tasks and personal choices. Another important point is that the dynamic daylight performance metrics are generally supposed to be measures for buildings with respect to their energy efficiency [6]. The average daylight factor, on the other hand, can be considered as a good indicator of the appearance of a room [1]. The metrics are critical for designers to be able to balance these criteria, and make informed trade-offs among them [6].

\section{Daylight and Occupant Behaviour}

The design intentions of daylighting, in the context of daylight performance metrics, should also be associated with the evaluation of its effect on building users. In this study we use seating choice as a proxy for behaviour. Regarding the discussion about daylight and occupant behaviour, past studies give a mixed conclusion as to whether daylight affects behavioural decisions. Some studies suggest that daylight affects occupant behaviour whilst others do not, and this may be due to the differences in methodology. On the other hand, daylight and its interaction with the occupant seating preference, this being a proxy for occupancy behaviour, has not been extensively investigated. Table 1 summarises past studies of daylighting and seat choice behaviour.

In [7] on investigated the relationship between architectural environment of a room and the patterns of seating preferences exhibited by library users. The collected data suggested that there is a tendency for certain individuals to occupy the same seat numerous times, a preference to sit apart from others for privacy, and a preference to sit near the reserve desk when room density is sufficiently low to allow this choice. In [8] the researchers described a survey of seating usage in a library building with the aim of quantifying client usage patterns and identifying areas where seating was underutilised or deficient. The major factors that affected seat choice included close proximity to the main entrance, access to primary service points, and the light and airy nature of the seating. In [9] we can find a preference for working in the window zone in spite of the problem of 
glare. This was studied using a post-occupancy evaluation survey of 1800 people in 20 Danish office buildings. In [10] on find the recorded seat choice behaviour in a south-facing student union lounge with 69 seats over nine hours during three sunny days. The results suggest a tendency for participants to choose seating in areas with direct sunlight: away from the sunny areas, it was observed that participants preferred seats in relatively more open spaces. Overall, these data suggest that perceived and actual behaviour lead to the same conclusion, and raise issues of glare and privacy. One aspect missing from these studies is that whilst they have reported a tendency to sit near windows, they did not carry out any quantitative measurement of daylight. Without this it is not possible to correlate seating preference with daylight metrics or other quantitative measure.

Table 1 Summary of the methods used in past studies of daylight and seat choice.

\begin{tabular}{|c|c|c|}
\hline STUDY & METHOD & $\begin{array}{l}\text { OUTCOME: DID DAYLIGHT AFFECT OCCUPANT } \\
\text { BEHAVIOUR? }\end{array}$ \\
\hline $\begin{array}{l}\text { Fishman \& Walitt, } \\
\text { 1972, [7] }\end{array}$ & $\begin{array}{l}\text { - Observed occupants' seat choice in an open- } \\
\text { plan, daylit, college room. } \\
\text { - Observation period: 8:00am-9:00am over two } \\
\text { semesters in the fall 1970 and spring } 1971 \text {. } \\
\text { - No daylight measurement. }\end{array}$ & $\begin{array}{l}\text { - UNKNOWN effect of daylight. } \\
\text { - Participants preferred to sit near the book-request desk } \\
\text { when room density was sufficiently low to allow this } \\
\text { choice, and apart from others for privacy } \\
\text { - Seat choice was affected by habit (a tendency for certain } \\
\text { individuals to occupy the same seat on repeated visits to } \\
\text { the library) }\end{array}$ \\
\hline $\begin{array}{l}\text { Organ \& Jantti, } \\
\text { 1997, [8] }\end{array}$ & $\begin{array}{l}\text { - Observation of occupants' seat choice in a } \\
\text { daylit library building. } \\
\text { - Observation period: Daily surveys were } \\
\text { timetabled to occur at 10am, } 1 \mathrm{pm} \text { and 3.30pm } \\
\text { from } 20 \text { June to } 30 \text { October } 1996 \\
\text { - No daylight measurement. }\end{array}$ & $\begin{array}{l}\text { - YES: It was observed that the most popular areas were } \\
\text { quiet, well lit and adjacent to windows. } \\
\text { - Wall seating was preferred to the more exposed areas or } \\
\text { aisle seating, with seats located adjacent to windows and } \\
\text { on the sunny eastern or northern aspects being the most } \\
\text { popular. }\end{array}$ \\
\hline $\begin{array}{l}\text { Christoffersen et al., } \\
\text { 2000, [9] }\end{array}$ & $\begin{array}{l}\text { - A survey carried out in } 20 \text { Danish office } \\
\text { buildings during the spring and autumn of } \\
1997 . \\
\text { - The questionnaire focused on windows, } \\
\text { daylight, sunlight, and artificial lighting. } \\
\text { - Handed out to } 2340 \text { office workers (response } \\
\text { percentage 78). }\end{array}$ & $\begin{array}{l}\text { - YES: Participants preferred seats in the window zone. } \\
\text { - Participants were less satisfied in the mid-zone or the } \\
\text { rear-wall zone, when compared to the window zone. } \\
\text { - The degree of satisfaction increased with increasing } \\
\text { daylight factor. } \\
\text { - The occupants' assessment of the daylight illumination } \\
\text { level in the office corresponded very well with the actual } \\
\text { measured daylight factors. }\end{array}$ \\
\hline $\begin{array}{l}\text { Wang \& Boubekri, } \\
\text { 2009, [10] }\end{array}$ & $\begin{array}{l}\text { - Observation of occupants' seat choice in in a } \\
\text { south-facing student union lounge. } \\
\text { - Observation period: } 1 \mathrm{pm}-4 \mathrm{pm} \text { on three } \\
\text { consecutive afternoons during mid-April } \\
\text { ( } 9 \text { hours in total) } \\
\text { - No daylight measurement. }\end{array}$ & $\begin{array}{l}\text { - YES. Participants preferred seats in sunlight } \\
\text { - Away from sunny area, they preferred seats in more open } \\
\text { spaces }\end{array}$ \\
\hline
\end{tabular}

Rather than provide a quantitative measure of seat choice and daylight, these past studies have tended to divide the room into somewhat arbitrary zones to describe proximity to windows [7, 9, 10]. In [7] on divided the floor plan in half by two types of division- horizontal and diagonal. Also, in [10] on divided the area into five zones based on their distances to the sun patches on the floor and on average illuminance level. In other study [9] for offices, positioned at a maximum distance of $7 \mathrm{~m}$ from the windows, were divided into three zones: window zone, mid-zone and the rear wall zone. It was found that participants were less satisfied with daylight conditions in the mid-zone or the rear-wall zone, when compared to the window zone.

\section{Aim}

The aim of the study is to determine whether daylight affects behaviour in open plan daylit spaces, with seating preferences used as a quantitative measure for occupant behaviour, and subsequently which daylight metric best predicted this behaviour. This was done through comparison of seat choice (observations) against the established daylight metrics (simulations).

\section{Method}

The observations were made in two open plan spaces, both being reading areas in two Sheffield University libraries, Western Bank (WB) and the Information Commons (IC) (Figure 1). 
In both spaces, observations were recorded during the weekdays of a two-week period, 10 November to 21 November 2014. Observations were made at hourly intervals from 10:00 to 21:00. In this period, dusk fell in the period of 16:00 to 17:40. Observations were drawn before and after dusk to enable comparison of seat choice in periods when daylight could, and could not, affect choice, thus to isolate the effect of daylight from other parameters. Since the period of time between sunset and complete darkness is an important solar day benchmark, it was decided preferable to divide the observation period into two intervals: 10:00-14:00 and 18:00-21:00. It is assumed that if observations in the period 10:00 to 14:00 suggest different seat choices to those in 18:00 to 21:00, the cause is more likely to be daylight.
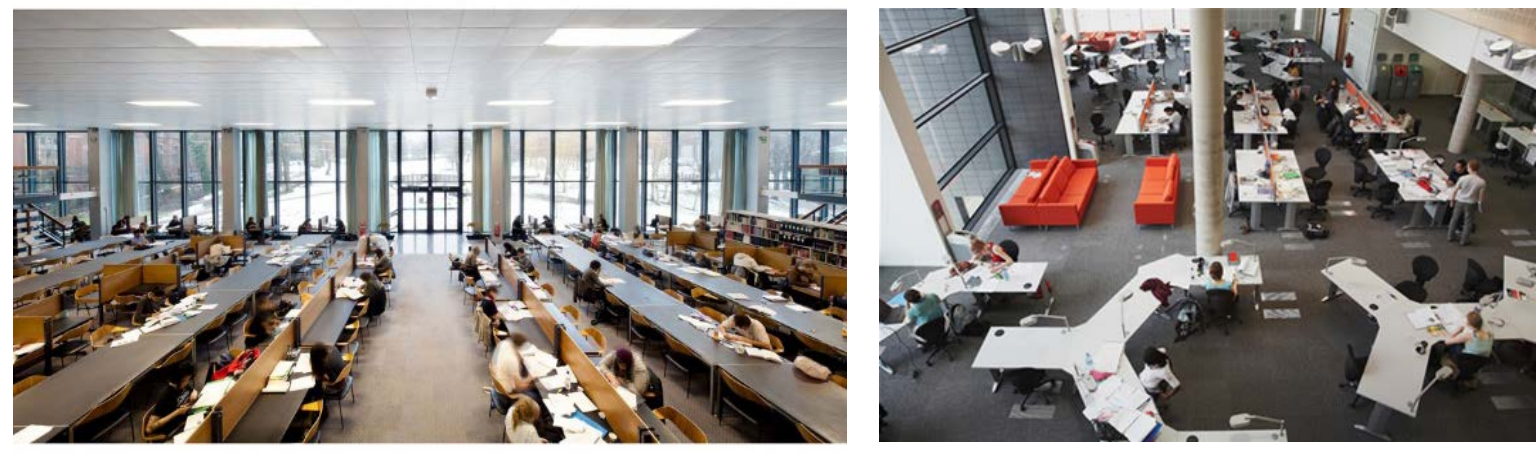

Fig. 1. Reading rooms in Western Bank Library (left) and Information Commons (right)

The reading area in WB mostly consisted of regular rows of study desks, whilst in IC the seats were generally angled in configuration (Figure 2 and Figure 3). Both reading rooms were large enough to accommodate the library users likely to choose the available seats, and daylight was available at the working plane during daytime, these were considered as major criteria for determining the limits of physical area. The selected study area in WB were divided into subareas, defined as observation zones, which can be used for ease of interpretation. As for IC, it was decided to calculate occupancy for each individual seat due to the irregularity of desk configuration.

Daily surveys of seat occupancy were carried out between 10:00-14:00 and 18:00-21:00. For IC, seat usage was calculated as the proportion of observation points for which each particular seat was occupied. For WB, in which the seating zones were not of equal size, seating usage in a zone was measured using Occupancy Rate as defined by the [11]. Occupancy Rate is the proportion of total capacity that was occupied, where total capacity is number of seats in an observation zone multiplied by the number of observation points.

Table 2 Radiance simulation parameters utilized in simulations

\begin{tabular}{ll}
\hline Parameter & Value \\
\hline Ambient bounces (ab) & 5 \\
Ambient divisions (ad) & 1000 \\
Ambient super-samples (as) & 20 \\
Ambient resolution (ar) & 300 \\
Ambient accuracy (aa) & 0.1 \\
\hline
\end{tabular}

Table 3 Material properties utilized in simulations (IC)

\begin{tabular}{lll}
\hline Material Properties & WB library & IC library \\
\hline Floors & 20\% Diffuse reflectance & 40\% Diffuse reflectance \\
Walls & 55\% Diffuse reflectance & 50\% Diffuse reflectance \\
Ceilings & 75\% Diffuse reflectance & $70 \%$ Diffuse reflectance \\
Desk surfaces & $50 \%$ Diffuse reflectance & $50 \%$ Diffuse reflectance \\
Outside ground & 20\% Diffuse reflectance & 20\% Diffuse reflectance \\
Glazing & 64\% Transmittance & $61 \%$ Transmittance \\
\hline
\end{tabular}




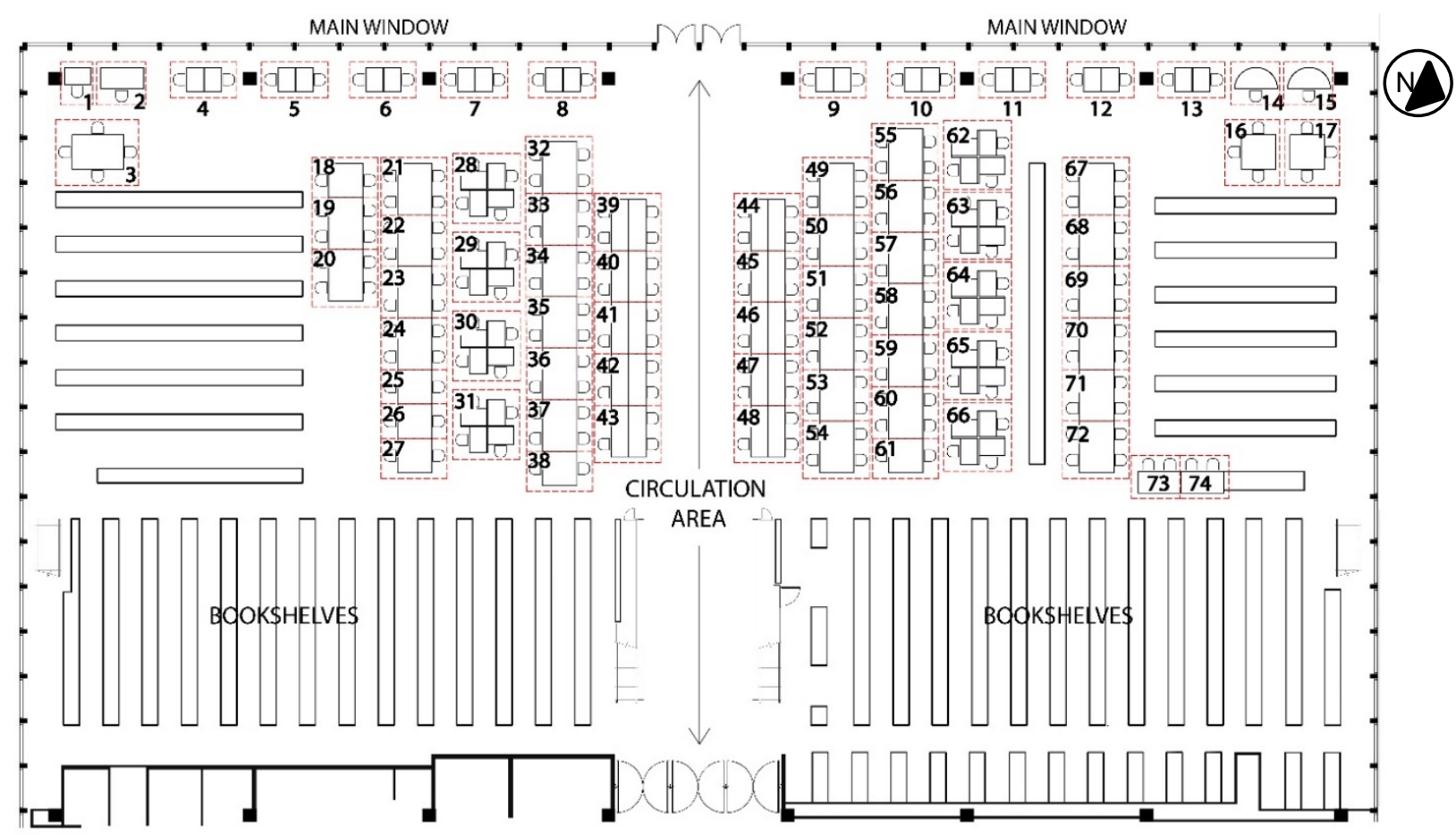

Fig. 2. Western Bank library seating plan (This space was divided into 74 observation zones)

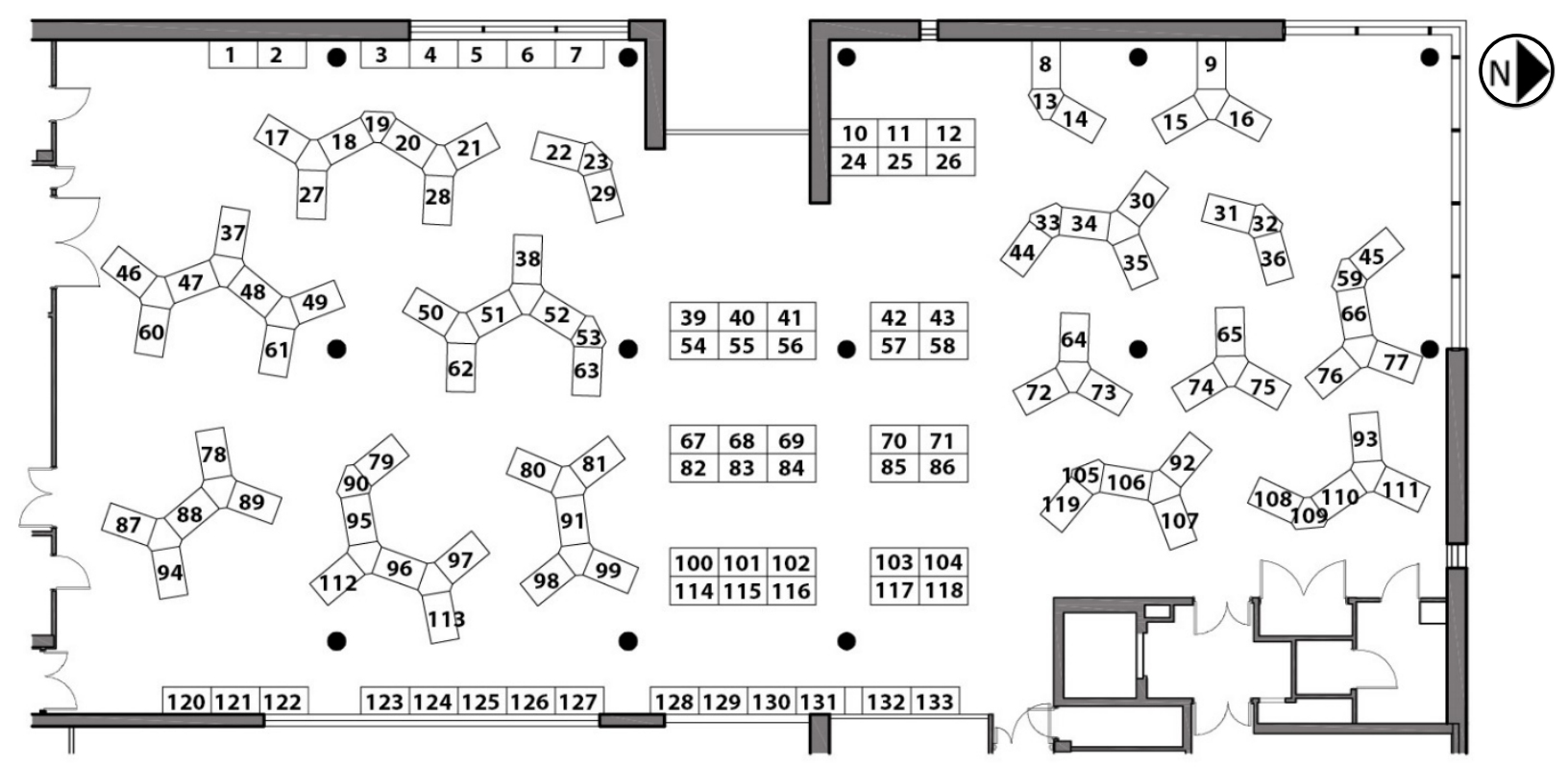

Fig. 3. Information Commons library seating plan (This space was divided into 133 individual seating areas)

Daylighting was analysed using simulation using DAYSIM within Autodesk Ecotect Analysis. DAYSIM uses a daylight coefficient approach combined with Perez all weather sky model [12] and the Radiance backward ray-tracer [13]. Daylight illuminance on the working plane is calculated for each zone during the simulation, and the sensor is located in the working plane, which is $0.75 \mathrm{~m}$ above the floor. Using a weather file for Sheffield, DAYSIM determined DF, DA and UDI for the observed space. As in the case of occupancy 
assessment, a simulation time step of one hour is considered. Table 2 and Table 3 show the Radiance simulation parameters and material properties that were used for these daylight simulations.

Both spaces are located in Sheffield, UK $\left(53.38^{\circ} \mathrm{N}, 1.48^{\circ} \mathrm{W}\right)$. In WB, the glazing area is more on the southwest facing facade, and limited on the south-east and north-west facades; whereas in IC the main glazing areas are mainly facing north and west. Table 4 shows the geometric properties of the two library spaces.

Table 4 Geometric properties of the two library spaces

\begin{tabular}{lll}
\hline & Western Bank Library & Information Commons \\
\hline Width $(\mathrm{m})$ & 26 & 16 \\
Length $(\mathrm{m})$ & 46 & 34 \\
Ceiling height $(\mathrm{m})$ & 5 & 7.6 \\
Workplane height $(\mathrm{m})$ & 0.75 & 0.75 \\
\hline
\end{tabular}

The shading devices in WB are automatically controlled and were open for every observation in this study. The reading area in IC is unshaded throughout the year. Window properties and blind/shade control for the two library spaces are shown in Table 5. The artificial lighting level was automatically controlled during the observation period, and it was simply measured during the night using a light meter.

Table 5 Window properties and blind/shade control for the two library spaces

\begin{tabular}{lll}
\hline & Western Bank Library & Information Commons \\
\hline Window area $\left(\mathrm{m}^{2}\right)$ & 410 & 124 \\
Glazing Type & Double-glazed & Double-glazed \\
Blind/shade control & Automatic & Unshaded \\
\hline
\end{tabular}

Horizontal desk top illuminances from electric lighting were measured in one building (IC), this being done after dark to ensure the measurements are electric lighting only. The average illuminance was approximately 120 lux, ranging from 32 to 290 lux.

\section{Results}

Figure 4 shows the comparison of occupancy rates between daytime (10:00-14:00) and night time (18:0021:00) for both WB and IC. For IC, occupancy rate was calculated for each individual desk whereas in WB it was calculated for each observation zone. If daylight had a significant and immediate impact on seating decisions, we would expect little correlation between seating at these times. Figure 4 however suggests a strong relationship, a tendency for a seating zone to be used with equal frequency at daytime and after dark, and thus that the influence of daylight is small.
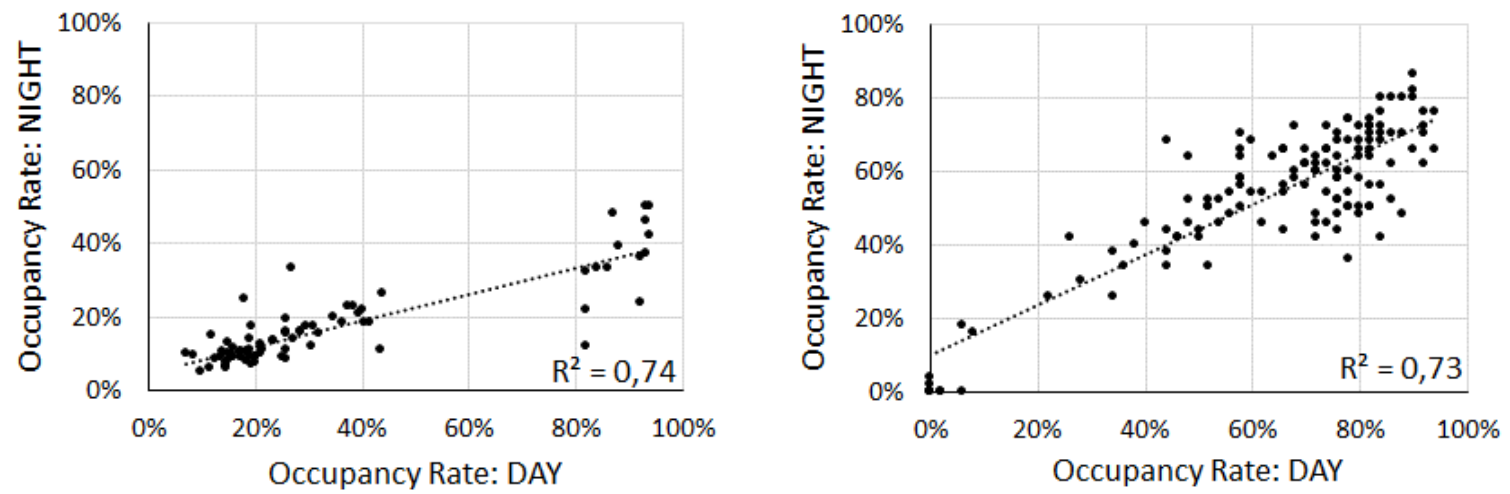

Figure 4. Comparison of occupancy rates between daytime and night time - Western Bank Library (left) and Information Commons (right). 
Figure 5 shows occupancy rate plotted against the three daylight metrics for daytime seating behaviour. While the IC data suggest negligible correlation between daylight and seat choice, the WB data exhibit a much stronger association. For both buildings, DF gives a higher degree of correlation with space use than does UDI or DA.

\section{Discussion}

\subsection{Seating regularity}

In these two sets of data, DF was a better predictor of seat choice than UDI or DA, as defined by the higher correlation (R2). However, the IC suggested negligible correlation between DF and seat choice $(\mathrm{R} 2=0.07)$ compared with that for WB (R2=0.68). One difference between these spaces is the regularity of the seating: in WB the seat are arranged largely in uniform rows whereas in IC they are arranged in an irregular pattern. There are a group of seats in IC that are more regular in layout (Figure 6a). For this group of seats the correlation between $\mathrm{DF}$ and seat choices increases $(\mathrm{R} 2=0.28)$. This suggests seating regularity may be an important factor.
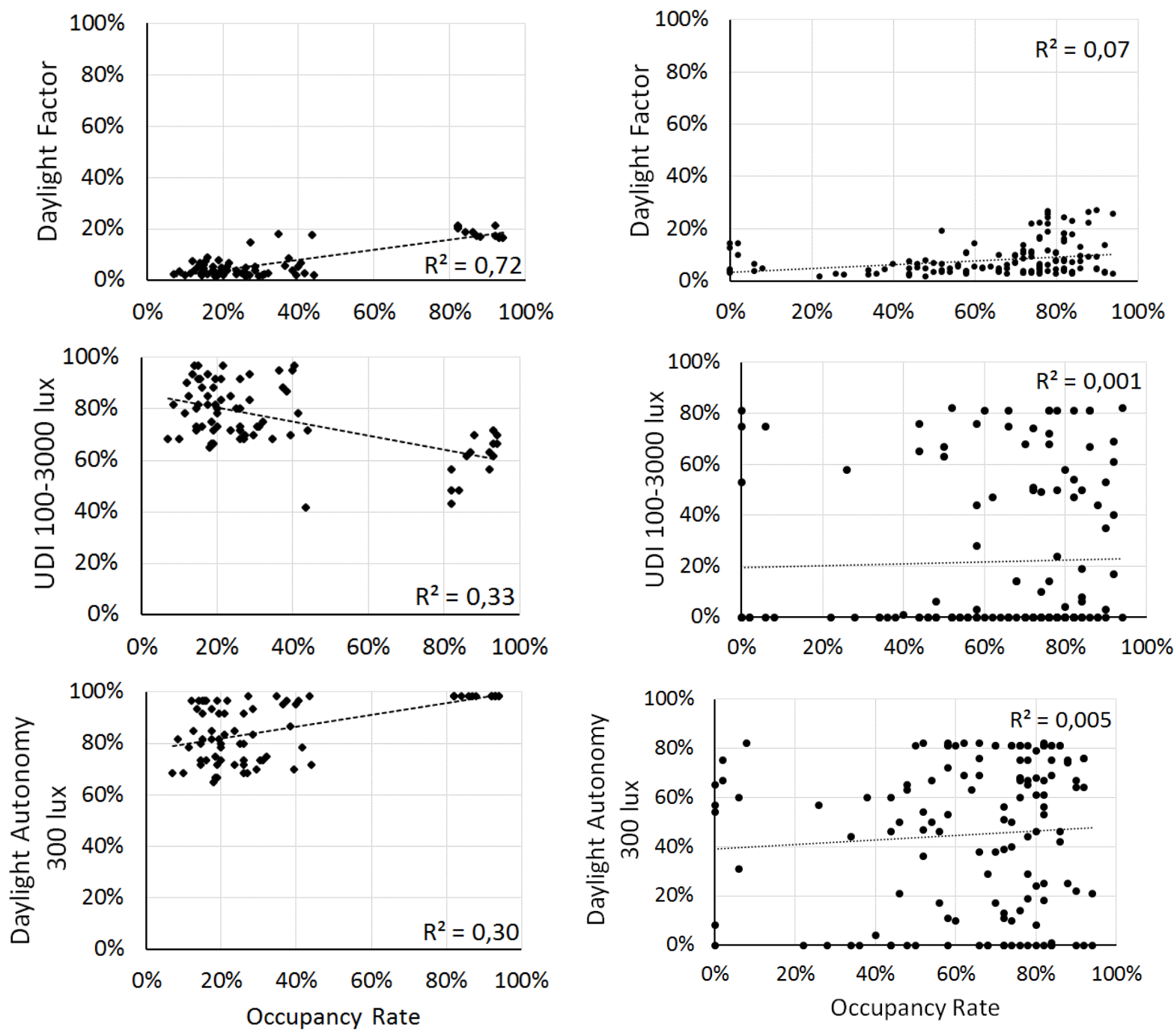

Figure 5. Comparison of daylight performance measures and seat choice - Western Bank Library (left) and Information Commons (right) 

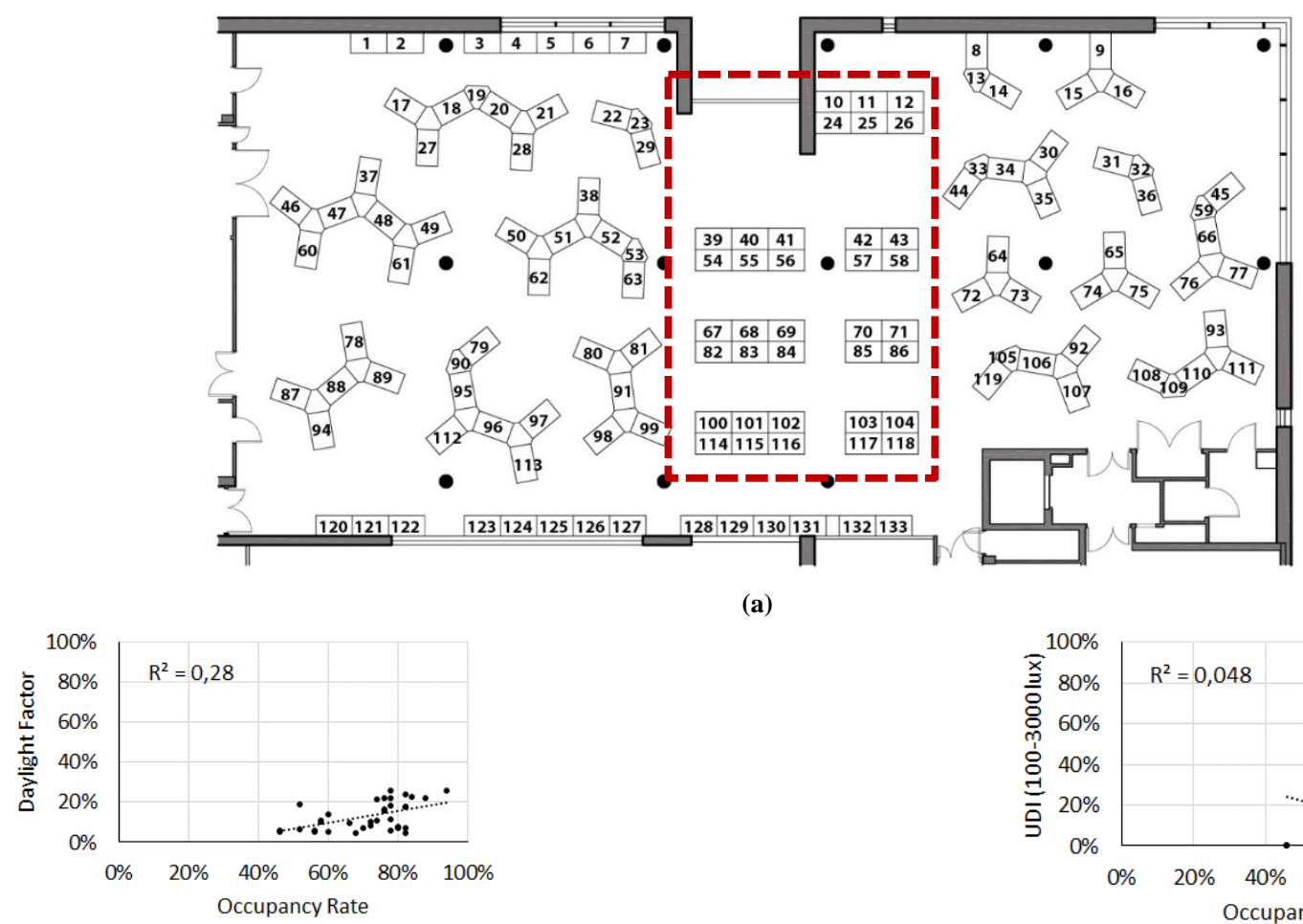

(a)
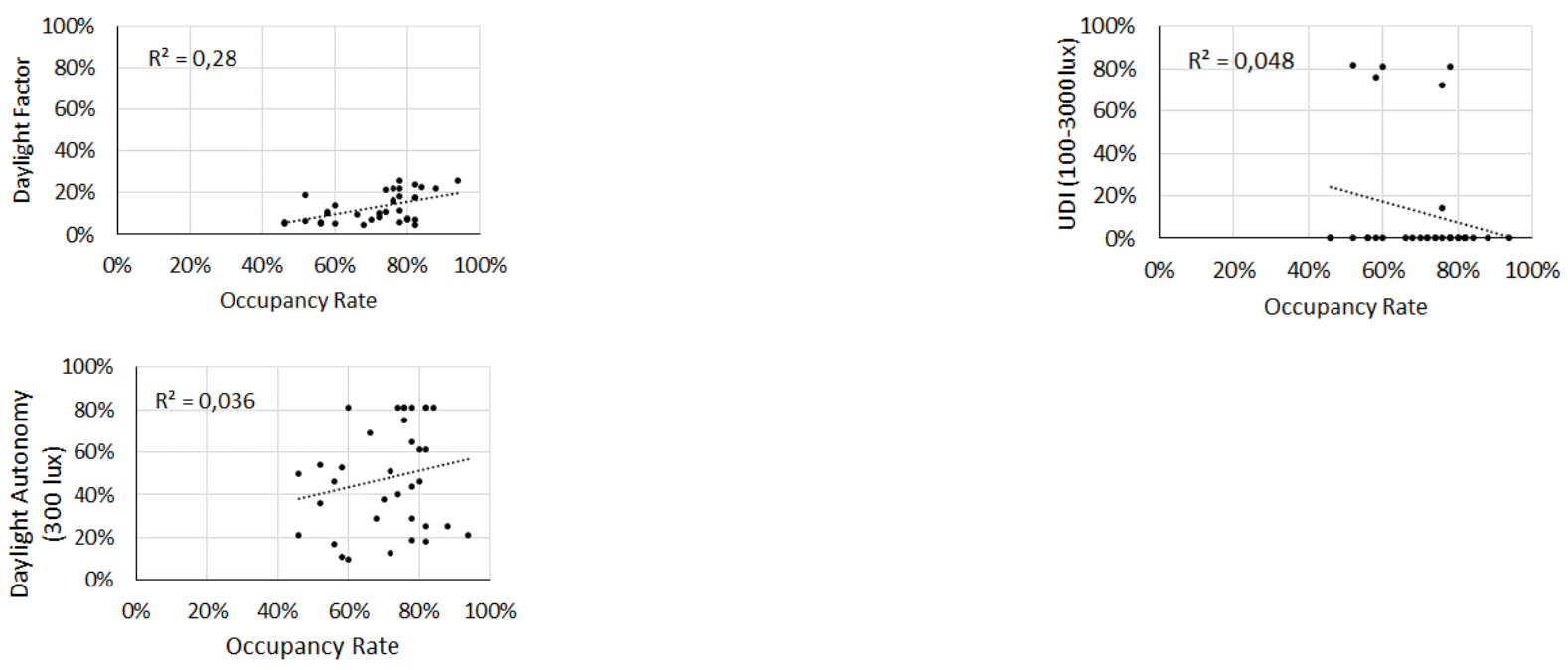

(b)

Figure 6. Comparison of daylight performance measures and seat choice for separated regular seats. 6(a) shows the regular seating area; 6(b) plots daylight quantity against occupancy rate.

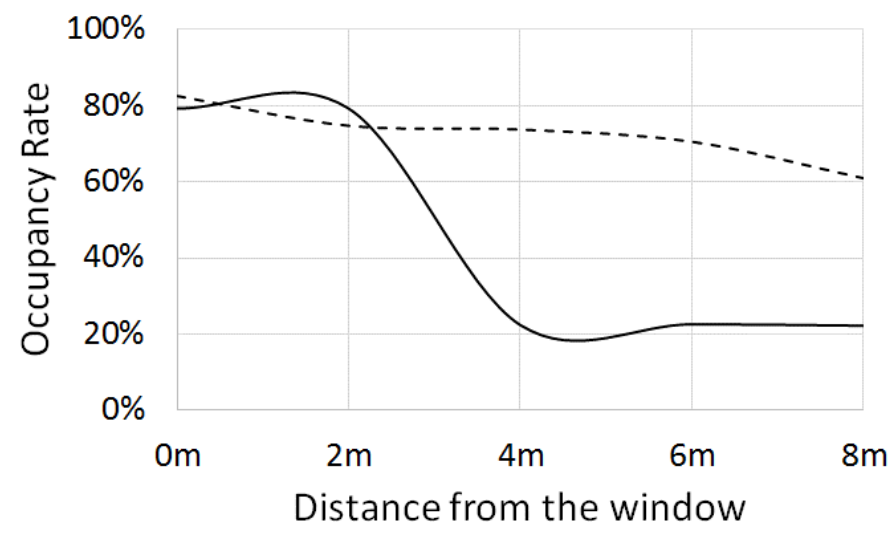

- - - Information Commons — Western Bank Library

Figure 7. Occupancy rate plotted against distance from the window 


\subsection{Distance from window}

We explore here a simpler measure of daylight, the plan distance from a seat to the nearest window, as was used qualitatively in previous work (Table 1). The results suggests a tendency for people to prefer to sit near windows: occupancy rates decrease as the distance from the windows increases (Figure 7). Although occupancy rates in both reading rooms decrease, they were not identical: the slope for the IC was much more gradual when compared to WB. For WB, there is a very slight increase in the occupancy rates through the bottom of the room.

\section{Conclusion}

This study examined the influence of daylight on occupant behaviour where occupant behaviour was defined as seat choice in two open plan daylit spaces. The results obtained are summarized as follows:

- The trend for sitting near the window found by previous studies is supported: Occupancy rates decrease as the distance from the window increases. This trend is stronger in WB than in IC.

- Comparison of seat occupancy between daytime and night time for both WB and IC suggests a strong relationship, a tendency for a seating zone to be used with equal frequency at daytime and after dark. This suggests a negligible influence of daylight.

- $\quad$ For both spaces, daylight factor gives a higher degree of correlation with seat use than does useful daylight illuminance or daylight autonomy.

- The degree of correlations between daylight and seat use are much lower for IC than for WB, which suggests that prediction might be better for regular seating pattern than irregular.

\section{REFERENCES}

[1] Tregenza, P. \& Wilson, M. - Daylighting: Architecture and Liahtina Desian. 1st ed. Routledge. 2011.

[2] Reinhart, C. F. - Daylighting Handbook I. Christoph Reinhart, USA, 2014.

[3] Moon, P. \& Spencer, D.E. - Illumination form a non-uniform sky. Transaction of the Illumination Engineering Society. 37, 707-726, 1942.

[4] Nabil, A. \& Mardaljevic, J. -Useful daylight illuminances: A replacement for daylight factors. Energy and Buildings, 38, 905-913, 2006.

[5] Nabil, A. \& Mardaljevic, J. - Useful Daylight Illuminance: A New Paradigm to Access. Daylight in Buildings. Lighting Res Tech. 37(1), 41-59, 2005.

[6] Reinhart, C., Mardaljevic, J., Rogers, Z. - Dynamic Daylight Performance Metrics for Sustainable Building Design. LEUKOS Volume 3 Issue 1, 2006.

[7] Fishman, D. \& Walitt, R. - Seating and Area Preferences in a College Reserve Room. College \& Research Libraries, 33 (4), 284-297, 1972.

[8] Organ, M., \& Jantti, M. - Academic Library Seating: A Survey of Usage, with Implications for Space Utilisation. Australian Academic and Research Libraries, 28, 205-216, 1997.

[9] Christoffersen,J., Johnsen,K., Petersen,E., Valbjorn,O., Hygge,S. - Windows and Daylight - A postoccupancy evaluation of Danish offices, Lighting 2000, CIBSE/ILE Joint Conference. University of York, UK. 112-120, 2000.

[10] Wang, N. \& Boubekri, M. - Behavioral Responses to Daylit Space: A Pilot Study. Journal of the HumanEnvironmental System, 12(1), 15-25, 2009.

[11] National Audit Office NAO. - Space Management in Higher Education: A Good Practice Guide. London: National Audit Office, 1996.

[12] Perez, R., Seals, R., Michalsky, J. - All-weather model for sky luminance distribution - preliminary configuration and validation. Solar Energy, 50(3), 235-245, 1993.

[13] Reinhart, C. F. \& Walkenhorst, O. - Dynamic RADIANCE-based daylight simulations for a full-scale test office with outer venetian blinds. Energy \& Buildings, 33(7), 683-697, 2001. 